\title{
Examining the Mediating Effect of Open Distance Learning Students' Study Engagement in Relation to Their Life Orientation and Self-Efficacy
}

\author{
Melinde Coetzee \\ Rudolf M. Oosthuizen \\ University of South Africa
}

\begin{abstract}
Address correspondence to Prof Melinde Coetzee, Department of Industrial and Organisational Psychology, University of South Africa, PO Box 392, Pretoria, Gauteng, South Africa, 0003. E-mail: coetzm1@ unisa.ac.za
\end{abstract}

This study reports on the mediating effect of study engagement (measured by an adapted version of the Utrecht Work Engagement Scale) in relation to students' life orientation (measured by the Orientation to Life Questionnaire) and their self-efficacy (measured by the Self-efficacy Scale). Participants included a non-probability sample of 127 predominantly early career (25-40 years), employed blacks and females enrolled for third year level ODL undergraduate studies in Industrial and Organisational Psychology. A quantitative survey design was followed, collecting primary data. Data analyses consisted of an analysis of correlations and three simple mediational models. The results revealed significant direct and indirect effects between the variables. Study engagement positively mediated the relationship between life orientation and self-efficacy. These findings contribute new knowledge that inform the design of learning and assessment activities aimed at enhancing ODL students' sense of the comprehensibility and meaningfulness of their studies, their engagement in their studies and beliefs about their capability to be successful in their studies.

\section{Keywords: life orientation, sense of coherence, study engagement, self-efficacy, open distance learning}

Increasing student retention, performance, motivation and success rates in the South African higher education open distance learning (ODL) context continues to be a key challenge (Müller, Prinsloo, \& Du Plessis, 2007; Prinsloo, Müller, \& Du Plessis, 2010; Prinsloo \& Subotzky, 2011). Open distance learning (ODL) institutions generally endeavour to ensure access to and affordability of learning to the adult student. Although ODL has a number of potential benefits for the student, not least of which is the ability to be a full time employee while pursuing further studies to update one's qualifications, knowledge and skills, being dispersed geographically and in time also pose several challenges to students which impact on their performance, motivation, success, and retention (Prinsloo \& Subotzky, 2011). ODL students generally face the challenge of balancing and dealing with the demands of multiple roles and responsibilities as employee, spouse, family care taker and student. Moreover, students may feel isolated and may experience a lack of support from their lecturers and fellow students as a result of limited interpersonal feedback and interaction which may influence their motivation and performance (Dzakira \& Idrus, 2003; Prinsloo \& Subotzky, 2011).

\section{Students's Personal Resources}

Research has revealed that students' motivation, beliefs, self-efficacy and engagement have a profound impact on their learning, performance and retention (ChanLin, 2009; Hartnett, 2012; Keller, 2008; Olwage, 2012; Roos, 2012; Viljoen, 2012; Xiao, 2012). Actively engaged students who have a strong sense of self-efficacy have been shown to be more productive, motivated, resilient and successful (Olwage, 2012; Roos, 2012). However, there seems to be a paucity of research on how ODL students' life orientation or general attitude toward the world and their work and personal lives influence their study engagement and self-efficacy. These psychological attributes seem to be important for students to succeed in an ODL context (Coetzee \& Oosthuizen, 2012). In this study, we were especially interested in examining the mediating effect of ODL students' study engagement in relation to their life orientation and self-efficacy. The study results may potentially contribute to improving teaching, learning and assessment activities which, in turn, may enhance student motivation, success and performance in the ODL context.

\section{Life Orientation}

Antonovsky's (1979) perspective on the construct of "life orientation" is of relevance to the present study. Antonovsky (1979) posits that individuals' general attitude towards the world and their own lives can be viewed as a particular stable dispositional orientation that reflects a sense of coherence toward life and the world in general. This life orientation or sense of coherence explains how people feel, how they perceive, behave and cope with demanding and challenging (stressful) situations, and how they keep healthy (Louw, Mayer, \& Baxter, 2012). The life orientation is mostly maturing by about 30 years of age and is considered relatively enduring. Although one's level of sense of coherence is formed through many life experiences, people's sense of coherence in terms of the world and their lives can also be influenced over time by various situations and contexts (Antonovsky, 1987).

Individuals' sense of coherence regarding the world and their lives is developed through the process of coming to understand one's life experiences in terms of their comprehensibility, manageability and meaningfulness (Antonovsky 1991). A sense of comprehensibility refers to the extent to which individuals are able to process familiar and unfamiliar stimuli as making cognitive sense, that is having a certain logic, order, structure and consistency rather than being noisy, chaotic, disordered, random, accidental, inexplicable and unpredictable (Antonovsky, 1987; De Villiers, 
2009; Louw et al., 2012). A sense of manageability indicates confidence in the perception that there are resources at one's disposal that are adequate to meet the demands posed by stimuli and that these resources can be developed through the experience of being able to effectively use one's own resources (Antonovsky, 1987; Louw et al., 2012). The resources at their disposal may refer to resources under the individual's own control or resources controlled by legitimate others, that is, friends, colleagues, or God, against the background of a history upon which one can count (Antonovsky, 1987; Marx, 2011). A sense of meaningfulness refers to the extent to which a person feels that life makes sense emotionally, that at least some of the problems and demands posed by living are worth investing energy in, are worthy of engagement and commitment, and are welcome challenges rather than burdens that one would rather do without (Antonovsky, 1987; Louw et al., 2012; Signe \& Solve, 2005).

The extent of how well developed the sense of coherence is in a person influences his or her general life orientation, willingness to invest energy and impacts on the individual and his or her work (Strümpfer, 1990). Individuals with high levels of sense of coherence are able to make cognitive sense of stressful and demanding situations and challenges (for example, having to balance multiple roles and responsibilities in terms of being an ODL student successfully) by activating personal or collective resources. In line with the reasoning of Mayer, Louw, and Louw, (2010) and Louw et al. (2012), we further propose that ODL students with a well developed sense of coherence may feel that they can deal with the challenges posed by their studies and their personal and work lives. They may also feel that their studies, work and life make sense and that the various demands they encounter are welcome challenges in which they like to invest their energy. Rothmann, Jackson, and Kruger (2003) found that high levels of sense of coherence contribute to the professional efficacy of individuals. Naude and Rothmann (2006) also found positive links between a strong sense of sense of coherence and engagement.

\section{Study Engagement}

Study engagement is viewed as a positive, fulfilling and work-related state of mind that is characterised by vigour, dedication (professional efficacy) and absorption (Schaufeli, Salanova, González-Romá, \& Bakker, 2002). Vigour is characterised by high levels of energy and mental resilience while working (or studying), the willingness to invest effort in one's work (or studies), and persistence in the face of difficulties. This energy can also relate to the level of mental effort or mental strength that individuals can put into doing something. Dedication or professional efficacy includes a sense of significance, enthusiasm, inspiration, pride and challenge, and the willingness of people to expend considerable time and effort in doing something meaningful. Absorption refers to the cognitive aspect where individuals are fully focused on something and experience a high level of concentration while performing a task. This includes being happily engrossed in one's work, so that time seems to pass quickly and one has difficulties in detaching oneself from work (Coetzee \& Oosthuizen, 2012; Coetzer \& Rothmann, 2007; Marx, 2011). High levels of energetic involvement with work or a task (such as studies) build professional efficacy (De Villiers, 2009). Strydom, Kuh, and Mentz (2010) regard high levels of student engagement as important for enhancing student success. Coetzee and Oosthuizen (2012) found ODL students' study engagement to be significantly related to their satisfaction with their studies. Research by De
Villiers (2009) indicates a positive and significant relationship between individuals' dedication and their sense meaningfulness (sense of coherence).

\section{Self-Efficacy}

Self-efficacy is considered an important component of an ODL student's self-concept because it is characterised by individuals' beliefs about their potentialities and perceived capabilities to attain designated types of performances and achieve specific results. Individuals' beliefs of personal competence affect their behaviour, the choices they make and the courses of action they pursue. People engage in tasks in which they feel competent and confident and avoid those in which they do not (Bandura, 1997, 2006). Self-efficacy beliefs help determine how much effort people will extend on an activity, how long they will persevere when confronting obstacles, and how resilient they will prove to be in the face of adverse situations - the higher the sense of self-efficacy, the greater the effort, persistence, and resilience (Pajares, 1996).

Self-efficacy beliefs are task- and situation-specific, and are therefore sensitive to contextual factors such the regulation of one's own motivation, thought processes, affective states and actions, or changing environmental conditions (Bandura, 1989; Pajares, 1996; Pintrich \& Schunk, 1995). Self-efficacy influences the cognitive appraisal of stressful situations (Bandura, 1997) such as for example having to balance the complexities and demands of one's ODL studies and personal and work lives. Research has shown that highly self-efficacious individuals perceive stressful situations as more challenging than stressful and that they have higher levels of optimism, self-esteem, self-regulation and life satisfaction (Leganger \& Kraft, 2003). Positive links have also been established between individuals' level of sense of coherence and their self-efficacy (Rothmann \& Malan, 2003) and students' self-efficacy and study engagement (Olwage, 2012). Student self-efficacy has also been related to their productivity (Stutton, Phillips, Lebnert, Bartle, \& Yokomizo, 2011).

\section{Goals of the Study}

The objective of the study was to examine the relation of ODL students' life orientation to their self-efficacy and the mediating effect of their study engagement to this relation. The increasing concerns about ODL students' performance and pass and throughput rates (Müller et al., 2007; Müller \& Du Plessis, 2010; Prinsloo \& Subotzky, 2011; Tladi, 2009) clearly underscore the need for research on these psychological attributes. Considering that students' engagement in their studies and self-efficacy have been related to their performance and productivity, this research seems important. Moreover, the importance of the present research is further underscored by the seemingly limited research on these psychological variables in the South African ODL context.

The specific research questions were:

- Does ODL students' life orientation significantly and positively relate to their self-efficacy?

- To what extent does ODL students' study engagement mediate the relation between their life orientation and self-efficacy? 


\section{Method}

\section{Participants}

The participants were a non-probability sample of 127 adults employed in the South African Service Industry who were enrolled for third year level undergraduate studies in Industrial and Organisational Psychology at a higher education open distance learning (ODL) institution. The sample predominantly constituted $66 \%$ blacks and $34 \%$ whites, and $71 \%$ females in the entry and establishment phases of their careers - 25-40 years $(70 \%)$. The sample of participants was employed at management/supervisory (52\%) and staff level positions (48\%).

\section{Measurements}

The participant students completed the following measures: the Orientation to Life Questionnaire (Antonovsky, 1987), Utrecht Work Engagement Scale (Schaufeli et al., 2002) and the Self-Efficacy Scale (Sherer \& Maddux, 1982). They also provided demographics data.

Life orientation. Life orientation was measured by using the Orientation to Life Questionnaire (OLQ) (Antonovsky, 1987). The OLQ is a self-rated, multi-factorial measure that contains three subscales (comprehension, manageability, meaningfulness) consisting of a total of 29 items. Respondents are required to make a choice from a seven-point semantic differential scale with two anchoring phrases on a seven-point Likert-type scale ( $1=$ strongly disagree; 7 = strongly agree). The questionnaire is regarded as a reliable, valid and cross-culturally applicable instrument that has been extensively studied in multiple settings in the South African context, with diverse populations and different languages (Bezuidenhout \& Cilliers, 2010; Van der Collf \& Rothmann, 2009). The Cronbach Alpha coefficients (internal consistency reliability) for the three subscales (as obtained for the sample of the current study) were as follows: comprehension (.68), manageability (.43), meaningfulness (.77).

Study engagement. An adapted version of the Utrecht Work Engagement Scale (UWES) (Schaufeli et al., 2002) was used to measure the levels of study engagement. The term "work" in the various items was replaced with the term "study" in the adapted version of the scale. The UWES includes 17 items measuring the engagement construct on three dimensions: vigour, dedication and absorption which are scored on a seven-point frequency-rating scale, ranging from zero (0) (never) to six (6) (every day). Confirmatory factor analysis (Schaufeli et al., 2002) demonstrated the factorial validity of the UWES. The Cronbach Alpha coefficients (internal consistency reliability) for the three subscales (as obtained for the sample of the current study) were as follows: vigour (.89), dedication (.84), absorption (.89)

Self-efficacy. Self-efficacy was measured by using the Self-Efficacy Scale (SES) (Sherer \& Maddux, 1982). The SES consists of 27 items. The statements deal with attitudes and feelings that people might have of themselves and their performance in a variety of tasks. Each item is answered on a seven-point Likert-type scale varying between one (1) (strongly agree) and seven (7) (strongly disagree), while four (4) indicates a midpoint. Low scores indicate a high level of self-efficacy (Marais, 1997). Cronbach's Alpha coefficients (internal consistency reliabilities) vary between .71 and .86 . The overall Cronbach Alpha coefficient for the scale (as obtained for the sample of the current study) was .79. Research in South Africa confirms the construct and criterion validity of the scale (Marais, 1997; Oosthuizen, 1998).

\section{Research Procedure}

Ethical clearance and permission to conduct the study were obtained from the management of the higher education institution that participated in the study. Questionnaires were mailed to the total population of 3000 students who were registered for third year level studies in Industrial and Organisational Psychology at the higher education institution for the particular year, yielding a response rate of $4 \%(n=127)$. The postal facilities of the institution were used to mail these questionnaires. Each questionnaire included a covering letter to obtain informed consent from the participants to use their responses for research purposes only. The covering letter explained the purpose of the research, procedure, potential benefits, confidentiality, anonymity, voluntary participation and withdrawal. Participants were requested to complete the questionnaires and return them by mail to the researcher using an enclosed return envelope.

\section{Data Analyses}

We used path-analysis to determine the extent to which the mediator variables (vigour, dedication, absorption) account for the direct and indirect relationship between the independent variable (life orientation) and the dependent variable (self-efficacy). We were therefore interested in examining the magnitude of the direct and indirect effects (standardised path coefficients) between the variables. To establish the unique effect of the mediator (study engagement) on the dependent variable (self-efficacy), we controlled for the independent variable (life orientation). We also controlled for gender and age.

\section{Results}

\section{Descriptive Statistics: Means, Standard Deviations and Frequencies}

Table 1 shows that the participants obtained the highest mean scores on the OLQ manageability $(M=50.10 ; S D=6.98)$ and UWES vigour $(M=32.46$; $S D=9.54)$ and absorption $(M=$ 32.30; $S D=10.71$ ) variables. The participants obtained the lowest mean scores on the OLQ meaningfulness $(M=44.53 ; S D=$ 8.31) and UWES dedication $(M=22.96$; $S D=5.73)$ variables. The high mean scores obtained on the SES (self-efficacy) suggest a low level of self-efficacy $(M=60.61 ; S D=14.44)$.

\section{Correlations}

Table 1 shows that the life orientation variables (comprehension, manageability and meaningfulness) negatively and significantly correlated with self-efficacy $(r \geq-.36 \leq-.45 ; p \leq .00$; medium practical effect). Similarly, the study engagement variables negatively and significantly correlated with self-efficacy $(r$ $=-.30=-.40 ; p \leq .00$; medium practical effect). The vigour variable correlated positively and significantly with comprehension $(r=.21 ; p \leq .05$; small practical effect) and meaningfulness $(r=$ $.25 ; p \leq .01$; small practical effect), while the dedication $(r=.31$; $p \leq .00$; moderate practical effect) and absorption $(r=.27 ; p \leq$ .01 ; medium practical effect) variables correlated positively and significantly with meaningfulness variable. The negative correlations between the self-efficacy variable and the life orientation and study engagement variables are expected because a low score on self-efficacy represents a positive adjustment and a high score represents a negative adjustment. 
Table 1

Descriptive Statistics: Means, Standard Deviations, Reliability Coefficients and Zero-Order Correlation Coefficients

\begin{tabular}{|c|c|c|c|c|c|c|c|c|c|c|}
\hline & Variables & $M$ & $S D$ & $\alpha$ & 1 & 2 & 3 & 4 & 5 & 6 \\
\hline 1 & Vigour (UWES) & 32.46 & 9.54 & .89 & & & & & & \\
\hline 2 & Dedication (UWES) & 22.96 & 5.73 & .84 & $.80^{* \star *}$ & & & & & \\
\hline 3 & Absorption (UWES) & 32.30 & 10.71 & .89 & $.90^{* * *}$ & $.79^{* * *}$ & & & & \\
\hline 4 & Comprehension (OLQ) & 49.59 & 8.93 & .68 & $.21^{*}$ & $\mathrm{n} / \mathrm{s}$ & $n / s$ & & & \\
\hline 5 & Manageability (OLQ) & 50.10 & 6.98 & .43 & $n / s$ & $n / s$ & $n / s$ & $.48^{\star \star *}$ & & \\
\hline 6 & Meaningfulness (OLQ) & 44.53 & 8.31 & .77 & $.25^{\star \star}$ & $.31^{\star * *}$ & $.27^{\star \star}$ & $.45^{\star \star \star}$ & $.49^{* * *}$ & \\
\hline 7 & Self-efficacy (SES) & 60.61 & 14.44 & .79 & $-.40^{\star \star \star}$ & $-.30^{\star \star *}$ & $-.38^{\star \star \star}$ & $-.44^{\star * *}$ & $-.36^{\star \star \star}$ & $-.45^{\star \star *}$ \\
\hline
\end{tabular}

Note. $\mathrm{n}=127 ;{ }^{* *} \mathrm{p} \leq .001 ;{ }^{* *} \mathrm{p} \leq .01 ;{ }^{*} \mathrm{p} \leq .05 ; \mathrm{r}=.50$ (large practical effect size); $\mathrm{r} \geq .30 \leq .49$ (medium practical effect size); $\mathrm{r} \leq .29$ (small practical effect size); $\mathrm{n} / \mathrm{s}$ : not significant. $M=$ mean; $S D=$ standard deviation; $\alpha=$ Cronbach's Alpha internal consistency coefficient.

\section{Mediation Effect: Study Engagement in Relation to Life Orientation and Self-Efficacy}

As shown in Figures 1,2 and 3, the relation between the participants' life orientation and their self-efficacy was significantly mediated by the three study engagement variables. All the study engagement variables turned to zero in the equation. Self-efficacy related negatively to the life orientation and the vigour, dedication and absorption variables. The negative regression weights (path coefficients) between the self-efficacy variable and the life orientation and study engagement variables are expected because a low score on self-efficacy represents negative self-beliefs about one's capabilities and a high score represents positive beliefs about one's capabilities (Pretorius \& Rothmann, 2001).

Life orientation had a significant direct effect on the vigour $(.23 ; p=.01)$, dedication $(.25 ; p=.004)$ and absorption $(.20 ; p=$ $.02)$, and self-efficacy $(-.49=-.50 ; p \leq .001)$ variables. Overall, the results suggest that when sense of coherence is high, the level of vigour, dedication and absorption (engagement) increases. In turn, vigour, dedication and absorption significantly increased the level of self-efficacy. The unique direct effects of the vigour $(-.25 ; p=.001)$, dedication $(-.14 ; p=.05)$, and absorption $(-.24 ; p=.002)$ variables on self-efficacy were moderate in magnitude. Bootstrapping results showed that life orientation had also a significant indirect effect on self-efficacy as mediated through the three study engagement variables. The confidence intervals for each indirect pathway excluded zero, providing thus significant support for the indirect effects between life orientation and self-efficacy as mediated by vigour ( $\mathrm{SE}=.06 ; \mathrm{Cl}=$ -.57 to $-.39 ; p=.02$ ); dedication (SE $=.06 ; \mathrm{Cl}=-.29$ to $-.04 ; p=$ .04 ); and absorption ( $\mathrm{SE}=.06 ; \mathrm{Cl}=-.60$ to $-.38 ; p=.01$ ). However, as shown in parentheses in figures 1,2 and 3, the strength of the relation of life orientation to self-efficacy was substantially reduced after accounting for the three study engagement mediators.

\section{Discussion}

The current study explored the relation of life orientation to self-efficacy and the mediating effect of study engagement to this relation. Previous research has established positive links between life orientation (sense of coherence) and self-efficacy (Rothmann \& Malan, 2003) and self-efficacy and study engagement (Olwage, 2012). The results of the present study added valuable new information to deepen understanding of the links between these variables by providing evidence of the mediating effect of ODL students' study engagement on the relation be-

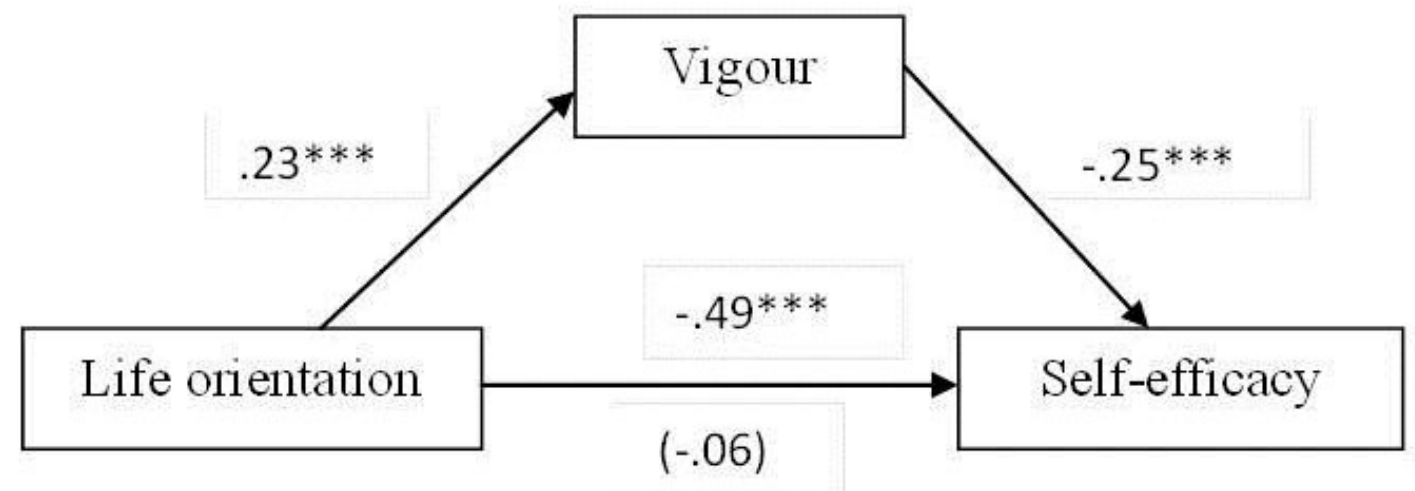

Figure 1. Mediation model examining the direct and indirect relation of sense of coherence and self-efficacy and the mediation effect of vigour. Values in parentheses represent the indirect effect of sense of coherence via vigour (mediator) on self-efficacy. All path coefficiencts are significant at $p \leq .001$. The standardised regression weights (path coefficients) are a bias-corrected bootstrap approximation at the 95\% corrected confidence interval (two-sided); $N=127$. 


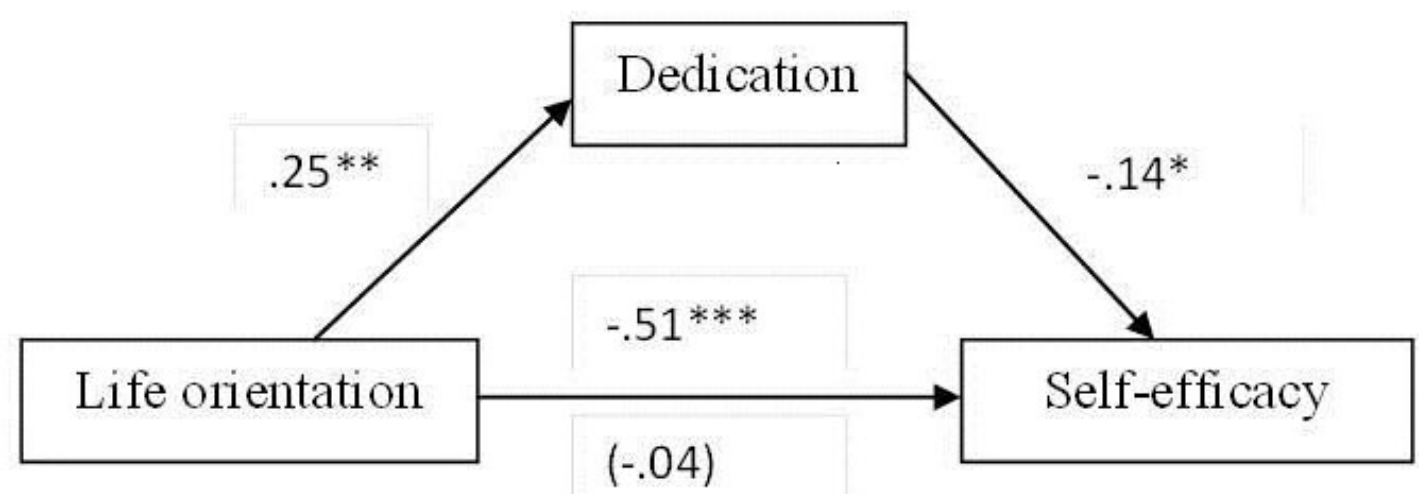

Figure 2. Mediation model examining the direct and indirect relation of sense of coherence and self-efficacy and the mediation effect of dedication. Values in parentheses represent the indirect effect of sense of coherence via dedication (mediator) on self-efficacy. All path coefficiencts are significant at $p \leq .05$. The standardised regression weights (path coefficients) are a bias-corrected bootstrap approximation at the 95\% corrected confidence interval (two-sided); $N=127$.

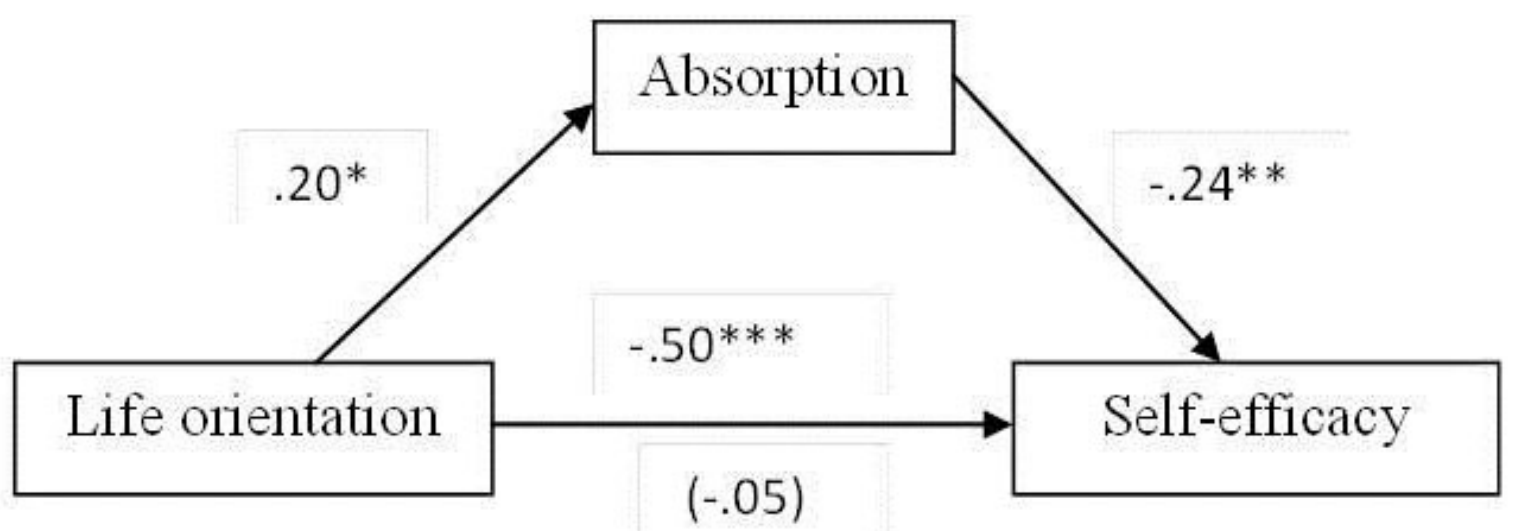

Figure 3. Mediation model examining the direct and indirect relation of sense of coherence and self-efficacy and the mediation effect of absorption. Values in parentheses represent the indirect effect of sense of coherence via absorption (mediator) on self-efficacy. All path coefficiencts are significant at $p \leq .01$. The standardised regression weights (path coefficients) are a bias-corrected bootstrap approximation at the 95\% corrected confidence interval (two-sided); $\mathrm{N}=127$.

tween their general attitude towards the world and their lives (life orientation) and their self-beliefs about their capabilities to deal with challenges (self-efficacy). Although the cross-sectional design in the present study precludes causal inferences, it may be that higher levels of sense of coherence facilitate higher levels of study engagement which, in turn, increases higher levels of self-efficacy.

The advantages of high levels of sense of coherence are salient in that it can be suggested that ODL students will interpret their world (personal life, work life and studies) with greater meaning (Nel, Crafford, \& Roodt, 2004; Strümpfer, 1990), viewing the balancing of these multiple roles as comprehensible and manageable. The significant and indirect paths between life orientation, study engagement and self-efficacy found in the mediation models suggest that making cognitive, emotional and motivational sense of the demands engendered by their multiple roles and viewing these as welcome challenges worthy of engaging and investing energies in (indicated by high levels of sense of coherence), significantly increased the participants' mental resilience and their willingness to put in effort and persistence in their studies (vigour). In agreement with research by Naude and Rothman (2003), the results further suggest that high levels of sense of coherence (strong life orientation) also significantly increased the participants' dedication to and mental absorption in their studies. A strong, positive life orientation also increased their self-efficacy. The results of our study further suggest that high levels of study engagement also increased the participants' self-efficacy (that is, their beliefs about their abilities to organise and successfully perform the multiple tasks associated with their multiple roles as ODL students). Salanova, Schaufeli, Martinez, and Bresò (2010) found that high levels of student engagement leads directly to performance while Bresò, Schaufeli, and Salanova (2011) found that higher self-efficacy generally leads to an increase in engagement among students, which enhances their performance.

The less strong indirect pathway observed between the participants' life orientation and their self-efficacy after accounting for the mediating effect of their level of study engagement sug- 
gests that although high levels of sense of coherence (positive life orientation) are important in facilitating student self-efficacy, increasing their levels of study engagement is more important to enhance their confidence in their abilities to successfully perform and persevere in complicated situations (such as managing the multiple roles and tasks expected from an ODL student). However, increasing students' sense of coherence (comprehensibility and meaningfulness) seems to be a precursor to increasing their study engagement levels. Helping ODL students' make cognitive sense of their studies (comprehensibility) and enhancing the meaningfulness thereof by helping them to see how their studies fit into their personal and work lives and that it is worthy of investment, commitment and engagement (Coetzee \& Oosthuizen, 2012) appear to be important in enhancing their engagement in their studies. Lee, Puig, Kim, Shin, Lee, and Lee (2010) also found that highly engaged students have higher levels of academic efficacy and lower levels of exhaustion and cynicism. Low levels of self-efficacy and negative views of the learning environment and social support available, lead to higher levels of burnout and a reduced sense of professional efficacy (feelings of incompetence and a lack of ability, skill and productivity in one's work) in students (Maslach, Leiter, \& Schaufeli, 2008; Olwage, 2012; Yang \& Farn, 2005).

\section{Implications for Open Distance Learning Practice}

Research by Bandura, Adam, and Beyer (1977) showed that a person does not initiate and persist in certain behaviours if they have doubts whether they can successfully perform them. An activity believed to exceed one's capability is avoided even though one might in fact have the ability to perform it. Increasing students' sense of self-efficacy and understanding the psychological variables that may influence it is therefore deemed important.

Academics involved in teaching, learning and assessment design need to help students see the meaningfulness of the learning and assessment activities they need to engage in and how these fit in with the overall course curriculum, and the students' professional career goals, personal and work lives (Coetzee \& Oosthuizen, 2012). Developing a sense of meaningfulness is considered the most important component in a person's life orientation; without it, life is experienced as a burden (Louw et al., 2012). High levels of meaningfulness may help develop a positive orientation towards one's studies and how these fit in with one's work and lives which, in turn, may increase the willingness to actively engage in one's studies. Strydom et al. (2010) posit that involving students actively in intellectually challenging and creative learning and assessment activities, setting high expectations for academic effort and student performance, active collaborative, real-world practical and reflective learning and assessment activities, prompt and constructive assessment feedback, and opportunities for students to discuss their grades, future plans and ideas with staff are important for enhancing student engagement.

Constructive and developmental feedback that increases students' beliefs about their capabilities to succeed in their studies may be valuable in further enhancing the self-efficacy levels facilitated by their high levels of study engagement. Research demonstrated that students' self-efficacy is greatly affected by the continuous feedback they receive for their academic tasks and performance, as well as their own attributions and interpretations of that feedback (Bandura, 1993; Yip, 2012). In their classical work, Wood and Bandura (1989) also proposed that an individual's self-efficacy is influenced by mastery experi- ences (i.e., personal success in past performance); modeling (i.e., vicarious learning by observing others), and social persuasion (i.e., realistic encouragement).

\section{Limitations and Recommendations for Further Study}

The conclusions about the findings of our study need to be considered in light of a number of limitations, each suggestive of promising directions in the area of research on enhancing ODL students' self-efficacy and performance. First, the study was cross-sectional in nature and thus the causal direction of relations between the variables cannot be ascertained. Longitudinal studies are needed to understand how students' life orientation evolves over time and how this influences their engagement in their studies and their self-efficacy. Such studies also need to consider variables relating to teaching, learning and assessment design in the ODL context and how these influence students' level of sense of coherence in terms of their life orientation, study engagement and self-efficacy.

Second, the participants in this study were enrolled as third-year level ODL students in one university in industrial and organisational psychology courses. They were mostly early career blacks and females employed in the South African services industry. The findings can therefore not be generalised to other educational, occupational, age, race and gender contexts. Replication studies, using independent samples drawn from other context are recommended. Notwithstanding these limitations, the study contributed valuable information in the light of the paucity of research on the life orientation, study engagement and self-efficacy of early career black female ODL students.

\section{Conclusion}

Overall, the results provided evidence of the importance of considering ODL students' sense of coherence (life orientation) in terms of their studies, work and lives, study engagement and self-efficacy in teaching, learning, and assessment design. More specifically, enhancing students' engagement in their studies by helping them to make cognitive, emotional and motivational sense of it will help to increase their sense of confidence in their ability to successfully engage and complete the tasks associated with their studies, personal and work lives.

\section{References}

Antonovosky, A. (1987). Unravelling the mystery of health: How people manage stress and stay well. San Francisco, CA: Jossey-Bass.

Antonovsky, A. (1979). Health, stress, and coping: New perspectives on mental and physical wellbeing. San Francisco, CA: Jossey-Bass.

Antonovsky, A. (1991). Personality and stress: individual differences in the stress process. Chichester, United Kingdom: John Wiley.

Bandura, A. (1989). Social cognitive theory. Annals of Child Development, 6, 1-60.

Bandura, A. (1993). Perceived self-efficacy in cognitive development and functioning. Educational Psychologist, 28(2), 117-148.

Bandura, A. (1997). Self-efficacy: The exercise of control. New York, NY: Freeman.

Bandura, A. (2006). Guide for constructing self-efficacy. In F. Pajares \& T. Urdan (Eds.), Self-efficacy beliefs of adolescents (pp. 307-337). Greenwich, CT: Information Age. 
Bandura, A., Adams, N. E., \& Beyer, J. 91977). Cognitive processes mediating behavioral change. Journal of Personality and Social Psychology, 35, 125-139.

Bezuidenhout, A., \& Cilliers, F. V. N. (2010). Burnout, work engagement and sense of coherence in female academics in higher-education institutions in South Africa. South African Journal of Industrial Psychology, 36(1), Art.\#872.10 pages. doi: 10.4102/sajip.v36i1.872.

Bresò, E., Schaufeli, W. B., \& Salanova, M. (2011). Can a self-efficacy-based intervention decrease burnout, increase engagement and enhance performance? A quasi-experimental study. Higher Education, 61, 339-355.

ChanLin, L. J. (2009). Applying motivational analysis in a web-based course. Innovation in Education \& Teaching International, 46(1), 91-103.

Coetzee, M., \& Oosthuizen, R.M. (2012). Students' sense of coherence, study engagement and self-efficacy in relation to their study and employability satisfaction. Journal of Psychology in Africa, 22(3), 315-322.

Coetzer, C.F., \& Rothmann,S. (2007). Job demands, job resources and work engagement of employees in a manufacturing organisation. Southern African Business Review, 11(1), 17-32.

De Villiers, M. (2009). The relationship between employee wellness and career anchors (Unpublished master's dissertation). University of South Africa, Pretoria.

Dzakira, H., \& Idrus, R. M. (2003). Teacher-learner interactions in distance education: A case of two Malaysian universities, Turkish Online Journal of Distance Education, 4(3). Retrieved from http://scholar.google.co.za/scholar?q=Turkish+online+ journal+of+distance+education

Emami, A. (2012). Distance education: its role in improving adult education. Life Science Journal, 9(3), 1781-1786.

Hartnett, M. (2012). Relationships between online motivation, participation, and achievement. More complex than you might think. Journal of Open, Flexible and Distance Learning, 16(1), 28-41.

Keller, J. M. (2008). First principles of motivation to learn and e-learning. Distance Education, 29(2), 175-185.

Lee, J., Puig, A., Kim, Y., Shin, H., Lee, J. H., \& Lee, S. M. (2010). Acadenic burnout profiles in Korean adolescents. Stress and Health, 26, 404-416.

Leganger, A., \& Kraft, P. (2003). Control constructs: Do they mediate the relationship between educational attainment and health behavior? Journal of Health Psychology, 8(3), 361-372

Louw, L., Mayer, C. H., \& Baxter, J. (2012). Exploring relationship between value- and life-orientation and job satisfaction. Acta Commercii, 1, 44-66.

Marais, C. P. (1997). Salutogenesis as paradigm in change management (Unpublished master's dissertation). University of South Africa, Pretoria.

Marx, A. A. (2011). The role of positive psychology constructs in employee coping. (Unpublished master's dissertation). University of South Africa, Pretoria.

Maslach, C., Leiter, M., \& Schaufeli, W. B. (2008). Measuring burnout. In C. L. Cooper \& S. Cartwright (Eds.), The Oxford handbook of organizational well-being (pp. 86-108). Oxford, United Kingdom: Oxford University Press.

Mayer, C. H., Louw, L., \& Louw, M. J. (2010). Sense of coherence and organizational commitment: $A$ case study in a se- lected South African parastatal. Competitive Paper, 22nd Annual Conference of the Southern African Institute for Management Scientists (SAIMS), Port Alfred, South Africa, 12-15 September.

Müller, H., Prinsloo, P., \& Du Plessis, A. (2007). Validating the profile of a successful first year accounting student. Meditari Accountancy Research, 15(1), 19-33.

Naude, J. L. P., \& Rothmann, S. (2006). Work-related well-being of emergency workers in South Africa. South African Journal of Psychology, 36, 63-81.

Nel, D.J., Crafford, A., \& Roodt, G. (2004). The relationship between sense of coherence and goal setting. South African Journal of Industrial Psychology, 30(2), 46-55.

Olwage, D. (2012). Predictors of burnout and engagement of university students (Unpublished master's dissertation). North-West University, Potchefstroom, South Africa.

Pajares, F. (1996). Self-efficacy beliefs in academic settings. Review of Educational Research, 66(4), 543-578.

Pintrich, P. R., \& Schunk, D. H. (1995). Motivation in education: theory, research, and applications. Englewood Cliffs, NJ: Prentice Hall.

Preacher, K. J., \& Hayes, A. F. (2008). Asymptotoc and resampling strategies for assessing and comparing indirect effects in multiple mediator models. Behavior Research Methods, 40, 879-891.

Pretorius, M., \& Rothmsann, S. (2001). Die verband tussen koherensiesin, lokus van beheer, selfdoeltreffendheid en werkstevredenheid [The relationship between sense of coherence, locus of control, self-efficacy and job satisfaction]. South African Journal of Industrial Psychology, 27(1), 25-31.

Prinsloo, P., Müller, H., \& Du Plessis, A. (2010). Raising awareness of the risk of failure in first-year accounting students. Accounting Education: An International Journal, 19(1/2), 203-218.

Prinsloo, P., \& Subotzky, G. (2011). Towards a framework and strategy for enhancing student success, retention, graduation and satisfaction at Unisa. Final Report Task Team 6, University of South Africa, Pretoria.

Roos, R. D. (2012). Relationship between first-year student retention, noncognitive risk factors, and student advising. All Graduate Theses and Dissertations, Paper 1167. Utah State University, Logan, Utah.

Rothmann, S., Jackson, L.T. B., \& Kruger, M. M. (2003). Burnout and job stress in a local government: The moderating effects of sense of coherence. South African Journal of Industrial Psychology, 29(4), 43-51.

Rothmann, S., \& Malan, H. (2003). Koherensiesin, selfdoeltreffendheid, lokus van beheer en uitbranding by maatskaplike werkers. [Sense of coherence, self-efficacy, locus of control and burnout of social workers.] South African Journal of Industrial Psychology, 29(4), 43-51.

Salanova, M., Schaufeli, W., Martinez, I., \& Bresò, E. (2010). How obstacles and facilitators predict academic performance: The mediation role of study burnout and engagement. Axiety, Stress \& Coping, 23(1), 53-70.

Schaufeli, W. B., Salanova, M., González-Romá, V., \& Bakker, A. B. (2002). The measurement of engagement and burnout and a confirmative analytic approach. Journal of Happiness Studies, 3, 71-92. 
Sherer, M., \& Maddux, J. E. (1982). The self-efficacy scale: Construction and validation. Psychological reports, 51, 663-671.

Signe, A., \& Solve, E. (2005). Family caregivers' subjective experiences of satisfaction in dementia care: Aspects of burden, subjective health and sense of coherence. Scandinavian Journal of Caring Sciences, 19(92), 157-168.

Strümpfer, D. J. W. (1990). Salutogenesis: A new paradigm. South African Journal of Psychology, 20, 45-52.

Strydom, J. F., Kuh, G. D., \& Mentz, M. (2010). Enhancing success in South Africa's higher education: Measuring student engagement. Acta Academica, 42(1), 259-278.

Sutton, G. W., Phillips, S., Lebnert, A. B., Bartle, B., \& Yokomizo, P. (2011). Strengths assessment, academic self-efficacy and learning outcomes in a Christian university sample. Journal of Psychology and Christianity, 30(1), 28-36.

Tladi, L. (2009). Unisa exam absence survey report. Department of Information and Strategic Analysis, University of South Africa: Pretoria.

Van der Colff, J. J., \& Rothman, S. (2009). Occupational stress, sense of coherence, coping, burnout and work engagement of registered nurses in South Africa. South African Journal of Industrial Psychology, 35(1), Art.\#423, 1-10. doi: 10.4102/sajip.v351L.423

Viljoen, C. (2012). First-year students' intention to stay: Engagement and psychological conditions (Unpublished master's dissertation). North-West University, Potchefstroom, South Africa.

Wood, R. E., \& Bandura, A. (1989). Social cognitive theory of organizational management. Academy of Management Review, 14, 361-384.

Wu, A. D., \& Zumbo, B. D. (2008). Understanding and using mediators and moderators. Social Indicators Research, 87, 367-392.

Xiao, J. (2012). Successful and unsuccessful distance language learners: An "affective" perspective. Open Learning, 27(2), 121-136.

Yang, H., \& Farn, C. K. (2005). An investigation of the factors affecting MIS student burnout in a technical-vocational college. Computers in Human Behavior, 21, 917-932.

Yip, M. C. W. (2012). Learning strategies and self-efficacy as predictors of academic performance: A preliminary study. Quality in Higher Education, 18(1), 23-34. 